\title{
Prescribing errors and uncertainty: Coping strategies of physicians and pharmacists in a tertiary university hospital
}

\author{
Emmanuel N. Anyika," Joy I. Okeke \\ Department of Clinical Pharmacy \& Biopharmacy, Faculty of Pharmacy, University of Lagos, Lagos, Nigeria
}

Received: December 10, 2015

Accepted: January 29, 2016

Online Published: April 5, 2016

DOI: $10.5430 /$ jha.v5n3p81

URL: http://dx.doi.org/10.5430/jha.v5n3p81

\begin{abstract}
Introduction: Prescribing errors and uncertainty are of increasing concern to health professionals due to their prevalence and implications for patient safety and wellness.

Objectives: To assess the coping strategies of doctors and pharmacists who experienced or observed prescribing errors and uncertainty in a tertiary university hospital, and the implications for therapeutic outcomes.

Methods: A self-assessment questionnaire was used to elicit information from a convenience sample of 94 physicians and 35 pharmacists of at least 2 years working experience in a tertiary hospital in Lagos, Nigeria, from October to December 2014. Ethical approval was sought and obtained for the study. The research instrument was validated by experts in the field of medicine, hospital pharmacy, and strategic management, and pilot-tested. Concerns and attitudes to committing/observing prescription errors and at different uncertainty levels were assessed. Also the outcomes of their encounters, specific actions taken by the two professional groups when faced with prescribing errors, causes of, and non-detection of prescribing errors, methods used to deal with the errors, and the extent to which pharmacy intervention was successful, were evaluated.

Results: Doctors and pharmacists (35.1\% vs. 40\%) admitted committing medication errors, while both professional groups (10.6\% vs. 20\%) admitted having avenues to discuss prescription errors. They also admitted prescribing or dispensing more, respectively when decision uncertainty was least. None of the doctors and few pharmacists admitted telling the patient about any prescription errors committed or observed respectively. There were varied responses on the causes of errors and non-detection of prescription errors. Coping strategies in terms of the use of technologies, medium and mode of communication, and use of continuing education to minimize errors, all fall below expectations for mitigating errors in prescribing and uncertainty.

Discussion and Conclusions: A number of variables assessed on good prescribing decisions and uncertainty were at variance with the studies from other countries. An organizational culture and structure that promote collaboration in prescribing decisions, infrastructural facilities, effective communication, enabling decision support systems, and relevant continuing education are needed to foster a care-process that is less prone to prescribing errors and uncertainty.
\end{abstract}

Key Words: Prescribing errors, Uncertainty, Coping strategies, Physicians, Pharmacists, University hospital

\section{INTRODUCTION}

Prescription errors and uncertainty are sources of concern to physicians, pharmacists, and nurses due to their far reaching implications for health outcomes in general practice and in the hospitals. An error is something incorrectly done through ignorance or inadvertence; a mistake, or a failure to complete

\footnotetext{
* Correspondence: Emmanuel N. Anyika; Email: emmaboogie22@yahoo.com; Address: Department of Clinical Pharmacy \& Biopharmacy, Faculty of Pharmacy, University of Lagos, Lagos, Nigeria.
} 
a planned action as intended, or the use of an incorrect plan of action to achieve a given aim. ${ }^{[1]}$ Errors in prescribing comprise irrational, inappropriate, and ineffective prescribing, under- and over- prescribing, and errors in writing the prescription. ${ }^{[2]}$ Prescribing errors ambiguously encompass prescribing faults and prescription errors. ${ }^{[2]}$ Medication error is defined as any preventable event that may cause or lead to inappropriate medication use or patient harm while the medication is in the control of a health care professional, patient or consumer. Such events may be related to professional practice, health care products, procedures, and systems, including prescribing, order communication, product labelling, packaging, and nomenclature, compounding, dispensing, distribution, administration, education, monitoring, and use. ${ }^{[3]}$ Medication errors could be classified into: contextual (time, place), modal (omission, substitution), and psychological (human related) categories. ${ }^{[2]}$ Four broad types of medication errors based on the psychological class are: knowledgebased errors (through lack of knowledge), ruled-based errors (using bad rule or misapplying good rule), action-based errors (slips in attention), and memory-based errors (lapses). ${ }^{[2]}$ Mistakes, slips and lapses are called active failures while latent factors are those characteristics of operating systems that make prescribers susceptible to error (unsafe environment) Prescribing is a staged process rather than a single event, and comprises patient information gathering, clinical decision making, communication of prescribing decision, and monitoring and review of therapy. ${ }^{[4]}$ Velo and Minuz ${ }^{[5]}$ stated that any step in the prescribing process can generate errors such as slips, lapses, or mistakes, as in unintended omissions in the transcription of drugs. Other identified prescribing errors and prescribing faults emanate from dose selection, omitted transcription, and poor handwriting. Also identified were: inadequate knowledge or competence and incomplete information about the clinical characteristics, and previous treatment of individual patients, use of potentially inappropriate medications, unsafe working environment, complex or undefined procedures, and inadequate communication among members of the health care team. Prescription errors also arise from failure to obtain accurate medication history, oversight, prescribing uncertainty and lack of prescribing guidelines. ${ }^{[6]}$ Of the different types of medication errors: prescription, dispensing, administration, monitoring, compliance, clerical, and potential errors, the most common and biggest contributors to about $70 \%$ of the errors are prescription errors. ${ }^{[7]}$ Patient safety incidents are caused by the complex nature of prescribing errors and a wide range of error-producing conditions (environment, team, task, individual and patient) ${ }^{[8]}$

Uncertainty is a fact of life for every health care practitioner and is regarded as central in the diagnosis of illness and in the processes of its alleviation. ${ }^{[9]}$ Judgment and decision tasks are uncertain in healthcare, which pose a barrier to the provision of quality health worldwide. ${ }^{[10,11]}$ Baumann $e t$ $a .^{[12]}$ suggest that uncertainty occurs at more than one level, employing the term micro- and macro-uncertainty. Communicating important uncertainties about the benefits and harms of prescription drugs to the public would affect consumer choices. ${ }^{[13]}$ An uncertain prescription could lead to medical malpractice actions and litigations. ${ }^{[14]}$ Schneider et al. ${ }^{[15]}$ described how general practitioners (GPs) deal with uncertainty to gain insight into decisional process. Shared decision making, doctor-patient relationship, trust and mutual respect, communication skills and evidence-based medicine, were approaches to dealing with uncertainty in general practice. ${ }^{[16]}$ Uncertainty about generic drug quality causes prescribing physicians to wait for more information before switching to the generic version or discourage prescribing it at all. ${ }^{[17]}$

Coping differences between young and experienced GPs in primary care were assessed. ${ }^{[18]}$ Over-confidence is a risk factor for diagnostic error in medicine. ${ }^{[19]}$ Junior doctors were aware of their prescribing errors, yet were confident in their prescribing skills and apparently complacent about the potential consequences. ${ }^{[20]}$ The risk of loss of reputation, disciplinary actions and embarrassment exists if prescribing errors are reported. ${ }^{[21]}$ Resident doctors would cope better and benefit more from learning opportunities where medical errors are discussed with peers and supervisors. ${ }^{[22]}$ Doctors' prescribing decisions were strongly influenced by the relationships with other team members, physician-patient relationship, and the pharmaceutical industry. ${ }^{[23]}$ Folksman et $a l .{ }^{[24]}$ derived eight distinct strategies of coping with stressful conditions: confrontative, seeking social support, planful problem-solving, self-control, distancing, positive appraisal, accepting responsibility and escape/avoidance. $\mathrm{ASHP}^{[25]}$ recommended that pharmacists should make themselves available to doctors and nurses to offer information and advice about the therapeutic drug regimens and correct use of medications; and should never assume or guess the intent of confusing medication orders. Coping with problems associated with prescribing errors requires a multi-disciplinary approach, which adopts the attitude of no blame, enhanced competence, controlling the environment, and changing the organizational culture. ${ }^{[21,26]}$ Avoiding medication errors is important in balanced prescribing, which is the use of medication that is appropriate to the patient's condition and, within the limits created by the uncertainty that attends therapeutic decisions, in a dosage regime that optimizes the balance of benefits to harm. ${ }^{[3]}$

The aims of this study therefore are to assess the coping 
strategies of physicians and pharmacists who experienced or observed prescribing errors and uncertainty; and the implications for patient outcomes in a tertiary hospital in Lagos.

\section{MATERials AND METHOdS}

A survey research instrument in the form of self-assessment questionnaire was used to elicit information from physicians and pharmacists in the university hospital. The questionnaire was developed using pertinent questions associated with committing prescription errors or observing/recognizing prescription errors and uncertainty, and the coping behaviour towards achieving patient wellness. Inclusion criteria are physicians (prescribers) and pharmacists who supervise or fill the prescriptions; with at least two years post graduation experience. Physicians and pharmacists, who have less than two years post graduation experience in the tertiary hospital, are excluded. Nurses are also excluded to limit the scope of the study and avoid delving into administration errors, which are mainly in the domain of nursing profession.

Ethical approval for the study was sought and obtained from the Ethical Committee of the College of Medicine, University of Lagos. The research instrument section for physicians was validated by a professor of Medicine in the College of Medicine of the University of Lagos, who made necessary adjustments and corrections; while a deputy director (phar- macist) in the Lagos University Teaching Hospital (LUTH) validated the questionnaire section for pharmacists. Also an Associate Professor in the Faculty of Business Administration of the University of Lagos, who is vastly experienced in strategic management, validated the aspects that deal with uncertainty factors. The instrument was pilot-tested before use.

A total of 250 questionnaires were prepared and used for the study. LUTH has about 490 doctors (within the inclusion criteria) comprising 60 consultants, 400 resident doctors and 30 medical officers, out of which only 94 physicians completed the questionnaires mostly in captive situations, before the Grand Rounds. Also 50 pharmacists consisting of 4 deputy directors, 6 assistant directors, 7 chief pharmacists, 6 principal pharmacists, 24 senior pharmacists and 3 pharmacists, out of which 35 completed the research questionnaire.

Participants' fears/concerns and attitudes to committing/observing prescribing errors and uncertainty were assessed. Medication error is sometimes used since the term includes prescription, dispensing, and administrative errors familiar to the two professional groups. Also investigated were the possibilities of litigation and error reporting, prescribing or dispensing at different uncertainty levels (see Table 1).

Table 1. Concerns about committing medication errors and uncertainty

\begin{tabular}{|c|c|c|c|}
\hline & $\begin{array}{l}\text { Doctors }>2 \text { years post } \\
\text { graduation experience }(n=94)\end{array}$ & $\begin{array}{l}\text { Pharmacists }>2 \text { years post } \\
\text { graduation experience }(n=35)\end{array}$ & $p$-value \\
\hline Has committed medication error in the past one year & $33(35.1 \%)$ & $14(40.0 \%)$ & $.607^{*}$ \\
\hline Afraid of committing medication error & $11(11.7 \%)$ & $14(40.0 \%)$ & .0003 \\
\hline $\begin{array}{l}\text { Sometimes worried about possibility of patient discovering } \\
\text { error, or law suit }\end{array}$ & $5(5.3 \%)$ & $6(17.1 \%)$ & .0326 \\
\hline $\begin{array}{l}\text { Used computerized physician order entry or clinical decision } \\
\text { support system to reduce error and uncertainty }\end{array}$ & $4(4.3 \%)$ & $2(5.7 \%)$ & $.292^{* *}$ \\
\hline $\begin{array}{l}\text { See medication error reporting as avenue for improvement and } \\
\text { not punishment }\end{array}$ & $19(20.2 \%)$ & $21(60.0 \%)$ & .000 \\
\hline Prescribed or dispensed when decision uncertainty is very high & $8(8.5 \%)$ & $2(5.7 \%)$ & $.5967^{* *}$ \\
\hline Prescribed or dispensed when decision uncertainty is high & $23(24.5 \%)$ & $2(5.7 \%)$ & .0163 \\
\hline Prescribed or dispensed when decision uncertainty is low & $90(95.7 \%)$ & $32(91.4)$ & $.3395^{*}$ \\
\hline
\end{tabular}

* Critical level of significance $p \geq .05 ;{ }^{* *}$ Null hypothesis not rejected but Type I or II error more likely

The two professional groups were asked about the possible outcomes of their encounters, and attitudes to prescription errors and uncertainty. These include: having avenue to discuss the experienced/observed errors, acknowledgement of errors, attitudes including the degree of certainty about the occurrence of prescribing errors, and evidence-based practice and other variables (see Table 2). Specific actions taken by the two professional groups when they experienced prescribing errors were also investigated (see Table 3 ). Doc- tors were asked about the possible causes of physician prescription errors while pharmacists were asked of the possible causes of pharmacist non-detection of prescription errors (see Table 4). Finally the participants were asked of the methods used to deal with prescribing errors and uncertainty, including the medium and mode of communication of medication errors and uncertainty. Also assessed was the extent to which pharmacy intervention was successful and accepted, rejected or evidence-based practice preferred (see Table 5). 
Table 2. Encounter, attitudes and reporting of prescription errors and uncertainty

\begin{tabular}{|c|c|c|c|}
\hline & $\begin{array}{l}\text { Doctors }>2 \text { years post } \\
\text { graduation experience }(n=94)\end{array}$ & $\begin{array}{l}\text { Pharmacists }>2 \text { years post } \\
\text { graduation experience }(n=35)\end{array}$ & $p$-value \\
\hline $\begin{array}{l}\text { Have avenue to discuss prescribing error with } \\
\text { doctor/pharmacist }\end{array}$ & $10(10.6 \%)$ & $7(20 \%)$ & $.1601^{* *}$ \\
\hline $\begin{array}{l}\text { Doctor acknowledges prescription error and made corrections } \\
\text { or asked pharmacist to correct }\end{array}$ & $5(5.3 \%)$ & $3(8.6 \%)$ & $.4894^{* *}$ \\
\hline $\begin{array}{l}\text { Doctor asked pharmacist to fill prescription as such based on } \\
\text { evidence }\end{array}$ & $2(2.1 \%)$ & $2(5.7 \%)$ & $.292^{* *}$ \\
\hline $\begin{array}{l}\text { Doctor did not accept that prescribing error occurred when } \\
\text { pointed out }\end{array}$ & $2(2.1 \%)$ & $1(2.9 \%)$ & $.788^{* *}$ \\
\hline $\begin{array}{l}\text { Doctor did not accept that prescribing error occurred when } \\
\text { pointed out }\end{array}$ & 0 & 0 & - \\
\hline Called doctor or pharmacist to notify of prescription error & $1(1.1 \%)$ & $2(5.7 \%)$ & $.1250^{* *}$ \\
\hline $\begin{array}{l}\text { During encounter, participant feels very uncertain that } \\
\text { prescription error occurred }\end{array}$ & $2(2.1 \%)$ & $1(2.9)$ & $.788^{* *}$ \\
\hline $\begin{array}{l}\text { During encounter, participant feels uncertain that prescription } \\
\text { error occurred }\end{array}$ & 0 & 0 & - \\
\hline $\begin{array}{l}\text { During encounter, participant feels certain that prescribing } \\
\text { error occurred }\end{array}$ & $10(10.6 \%)$ & $7(20 \%)$ & $.1601^{* *}$ \\
\hline
\end{tabular}

Table 3. Participants' responses on what they did when they made/observed error

\begin{tabular}{llll}
\hline Process & $\begin{array}{l}\text { Doctors }>2 \text { years post } \\
\text { graduation experience }(\mathbf{n}=\mathbf{9 4})\end{array}$ & $\begin{array}{l}\text { Pharmacists }>\text { 2 years post } \\
\text { graduation experience }(\mathbf{n}=35)\end{array}$ & $\begin{array}{c}\boldsymbol{p} \text {-value } \\
\text { Tried to correct the error }\end{array}$ \\
Tried to hide the error & $40(42.6 \%)$ & $30(85.8 \%)$ & .000 \\
Told supervisor or colleague about the medication error & $2(2.1 \%)$ & $1(2.9 \%)$ & $.7883^{* *}$ \\
Told the patient and explained & $6(6.4 \%)$ & $3(8.6 \%)$ & $.6632^{* *}$ \\
Told the patient and apologized & 0 & $4(11.5 \%)$ & .0008 \\
\hline
\end{tabular}

Note. Adapted from Nevalainen et al. ${ }^{[18]}$; ${ }^{*}$ Critical level of significance $p \geq .05 ;{ }^{* *}$ Null hypothesis not rejected but Type I or II error more likely

Table 4. Participants' responses on causes of prescription error

\begin{tabular}{llll}
\hline Variable & $\begin{array}{l}\text { Doctors }>\text { 2 years post } \\
\text { graduation experience }(\mathbf{n}=\mathbf{9 4})\end{array}$ & $\begin{array}{l}\text { Pharmacists }>\text { 2 years post } \\
\text { graduation experience }(\mathbf{n}=\mathbf{3 5})\end{array}$ & $\boldsymbol{p}$-value \\
\hline Heavy work load & $67(71.3 \%)$ & $21(60 \%)$ & $.2203^{*}$ \\
Stress & $40(42.6 \%)$ & $11(31.4 \%)$ & $.2474^{*}$ \\
Environment not conducive & $11(11.7 \%)$ & $2(5.7 \%)$ & $.3140^{* *}$ \\
Distraction & $36(38.3 \%)$ & $8(22.9 \%)$ & $.1009^{*}$ \\
Limited knowledge of medication errors and uncertainty & $15(16 \%)$ & $10(28.6 \%)$ & $.1077^{*}$ \\
\hline
\end{tabular}

${ }^{*}$ Critical level of significance $p \geq .05 ;{ }^{* *}$ Null hypothesis not rejected but Type I or II error more likely

The variables were presented as percentages or as means with standard deviations. Comparison between the professional group variables were made using Fisher's exact test, while the $p$-values $(p \geq 0.05)$ are considered as significant at $95 \%$ confidence interval.

\section{RESULTS}

A total of 94 doctors and 35 pharmacists completed the questionnaire. Out of the sample populations, 51 doctors (54.3\%) and 6 pharmacists $(17.1 \%)$ were males respectively. The mean ages of physicians and pharmacists were 38.2 SD 5.6 years and $36.5 S D 6.3$ years respectively.

\subsection{Concerns about committing medication errors and uncertainty}

Concerns about committing medication errors and consequences, medication error reporting, prescribing or dispensing at different levels of uncertainty are presented (see Table 1). Both professional groups (35.1\% doctors and $40 \%$ pharmacists) admitted committing medication errors (prescribing and dispensing errors respectively) in the past one year. Doctors and pharmacists also prescribed and dispensed respectively at different levels of decision uncertainty. 
Table 5. Methods used by doctors and pharmacists to deal with prescribing errors and uncertainty

\begin{tabular}{|c|c|c|c|}
\hline Variable & $\begin{array}{l}\text { Doctors }>2 \text { years post } \\
\text { graduation experience }(n=94)\end{array}$ & $\begin{array}{l}\text { Pharmacists }>2 \text { years post } \\
\text { graduation experience }(n=35)\end{array}$ & $p$-value \\
\hline \multicolumn{4}{|l|}{ Coping with prescription errors \& uncertainty } \\
\hline Consult senior colleague & $7(7.4 \%)$ & $4(11.4 \%)$ & $.4685^{* *}$ \\
\hline Check official book for clarification & $57(60.6 \%)$ & $22(62.9 \%)$ & $.8116^{*}$ \\
\hline Use prescribing/dispensing technology & $4(4.3 \%)$ & 0 & $.2126^{* *}$ \\
\hline Doctor/pharmacist calls counterpart to clarify potential error & 0 & 0 & - \\
\hline \multicolumn{4}{|l|}{ Medium of Communication of Error \& Uncertainty } \\
\hline Written on the prescription & 0 & $9(25.7 \%)$ & .0000 \\
\hline Discussed over the telephone & 0 & 0 & $.1960^{*}$ \\
\hline Doctor-pharmacist as one-on-one & $3(3.2 \%)$ & $3(8.6 \%)$ & .0002 \\
\hline Through the patient & 0 & $5(14.3 \%)$ & $.1250^{* *}$ \\
\hline \multicolumn{4}{|l|}{ Mode of communication of error \& uncertainty } \\
\hline Accepts responsibility & $1(1.1 \%)$ & $2(5.7 \%)$ & $.2924^{* *}$ \\
\hline Confrontational & $2(2.1 \%)$ & $2(5.7 \%)$ & $.4672^{* *}$ \\
\hline Avoidance of the issue & $1(1.1 \%)$ & $1(2.9 \%)$ & - \\
\hline Positive appraisal of the issue & 0 & 0 & - \\
\hline Continuing education on medication error and uncertainty & 0 & 0 & - \\
\hline
\end{tabular}

${ }^{*}$ Critical level of significance $p \geq .05 ;{ }^{* *}$ Null hypothesis not rejected but Type I or II error more likely

\subsection{Encounters, attitudes and reporting of prescription errors and uncertainty}

Assessment of whether doctors and pharmacists have the avenue to discuss prescription errors and uncertainty with their counterparts is presented in Table 2. Only $10(10.6 \%)$ doctors and 7 (20\%) pharmacists admitted having avenue to discuss prescription errors.

\subsection{What respondents did when they made/observed prescription errors}

Participants' responses on what they did when they made/observed prescription errors are in Table 3. None of the doctors and few pharmacists admitted telling the patient about committing any prescription errors, nor explained/apologized for any such errors. Only few pharmacists admitted telling the patient about any prescription errors observed and explained/apologized for errors.

\subsection{Causes of prescribing errors and pharmacists' non- detection of prescription errors}

Doctors were asked the possible causes of prescription errors and pharmacist were asked of the possible causes of nondetection of prescription errors. There were varied responses reflecting the influence of these variables on the occurrence and detection of prescription errors (see Table 4).

\subsection{Methods used by doctors and pharmacists to deal with prescribing errors and uncertainty}

Methods used by doctors and pharmacists respectively to deal with prescribing errors and uncertainty are presented in
Table 4. The medium and mode of communication, among others show a very poor communication of prescription errors and uncertainty between the two professional groups. Only $4.3 \%$ of the doctors have used electronic prescribing support systems to minimize prescription errors, while no pharmacist has used computerized prescription order entry to minimize medication errors. All the participants admitted that no interdisciplinary educational program has ever been organized to reduce medication errors in the health facility.

\section{Discussion}

Medication errors seem to be common occurrence among physicians and pharmacists, as $31.5 \%$ and $40 \%$ of the two professional groups respectively admitted to having committed such errors. This is in line with other studies on health professionals. ${ }^{[27,28]}$ In our study, low percentages of doctors and pharmacists respectively, were afraid of committing medication errors (11.7\% and $17.1 \%)$ or appeared worried about the patient discovering error or filing law suit (5.3\% and $5.7 \%$ ). The outcome may be as a result of non-stringent enforcement of the law and culture-bound tolerance to medical errors (to err is human) in our environment, unlike higher results for physicians in other cultural settings. ${ }^{[18]}$ The adult literacy rate in the Nigeria population is about $56.9 \%,{ }^{[29]}$ and might have contributed to people not demanding for their right to quality health care if violated. Only $4.3 \%$ of the doctors have used clinical support systems to reduce prescription errors, while about $5.7 \%$ of the pharmacists have used computerized physician order entry or any electronic support system before. Unlike developed economies where the use 
of CPOEs has resulted in fewer call-backs from pharmacies to physicians for clarification, reduced preventable adverse drug events and cost of therapy, enhanced safety and quality of prescribing process, ${ }^{[30-32]}$ our study shows that the vital role of these supports systems in errors prevention is yet to be appreciated. Although CPOEs could add more layers of potential errors, the synergistic combination of steganography and cryptography technologies in medical prescription can properly provide security for patient's prescription. ${ }^{[33]}$ In our study, vast majority of doctors and pharmacists did not seem to bother or have fear of making mistakes. Other studies have shown that proactive approach to error reduction is achieved through education, information, effective communication and enhanced proficiency in prescribing. ${ }^{[18,34,35]}$ About 20\% of doctors and $60 \%$ of pharmacists in our study view medication error reporting as an avenue for improvement, not for punishment. Our findings fall below expectation when compared to other studies where the liability weighs on self reporting decisions. ${ }^{[9]}$ In our study, prescribing or dispensing errors under decision uncertainty seem to worsen as the uncertainty increases and vice-versa (see Table 2). These findings are in line with other research works. ${ }^{[9,10,18,36]}$ In line with other studies, fear and decision uncertainty seem to reduce with the accumulation of experience. ${ }^{[18,37]}$

Our study shows low percentages of doctors and pharmacists respectively featuring in the respective dimensions of: avenue to discuss prescribing errors when pointed out, notification or communication of errors among the professional groups, and increased uncertainty for the occurrence of errors. Other studies show that physicians are more willing to discuss with their colleagues but less willing to discuss with their patients. ${ }^{[8,21,26,38]}$ Over-confidence and miscommunication among health professionals observed in our study was also reported in other studies, ${ }^{[19,20]}$ and negate the fundamental right of the patient to quality care. Inter-professional collaboration on prescribing decisions, which is very much lacking in our setting, ${ }^{[34]}$ will reduce prescribing uncertainty and enhance patient outcome. ${ }^{[11,23,28]}$ Schneider et al. ${ }^{[15]}$ also emphasizes the importance of communicating uncertainty to patients as the need arises, for better health outcomes.

Apart from the first variable in Table 3, other variables respectively showed poor coping strategies by both professional groups. Unlike some developed countries where reporting liability weighs on self-reporting decisions, there is disparity in the complexity of documentation; thereby making comparisons in different economies inaccurate. Our study indicates the absence of prescribing guidelines, inadequate knowledge of how to carry the patients along in the matters concerning their health; fear of disciplinary action, inadequate commu- nication of uncertainty, conflict of acceptance of evidencebased medicine, and loss of respect. These are probably responsible for the poor communication and co-operation with the patients. In contrast, other studies show that collaboration with patients enhances the care-process to the patients' advantage. ${ }^{[15,39,40]}$ Lack of adequate co-operation among the two professional groups in our study tends to introduce Type I or Type II error ${ }^{[41]}$ in the analyses of results, due to the small sample sizes (zero in some cases) in some of the measures. To minimize medication errors, pharmacists should make themselves available to other health professionals, aimed at solving drug related problems ${ }^{[15]}$ and reducing decision uncertainties. Heavy workload, stress, burn-outs, unfavourable work environment, distraction, limited knowledge of prescription errors, and uncertainty were perceived causes of prescription errors in our study, as also observed in other studies. ${ }^{[18,42]}$

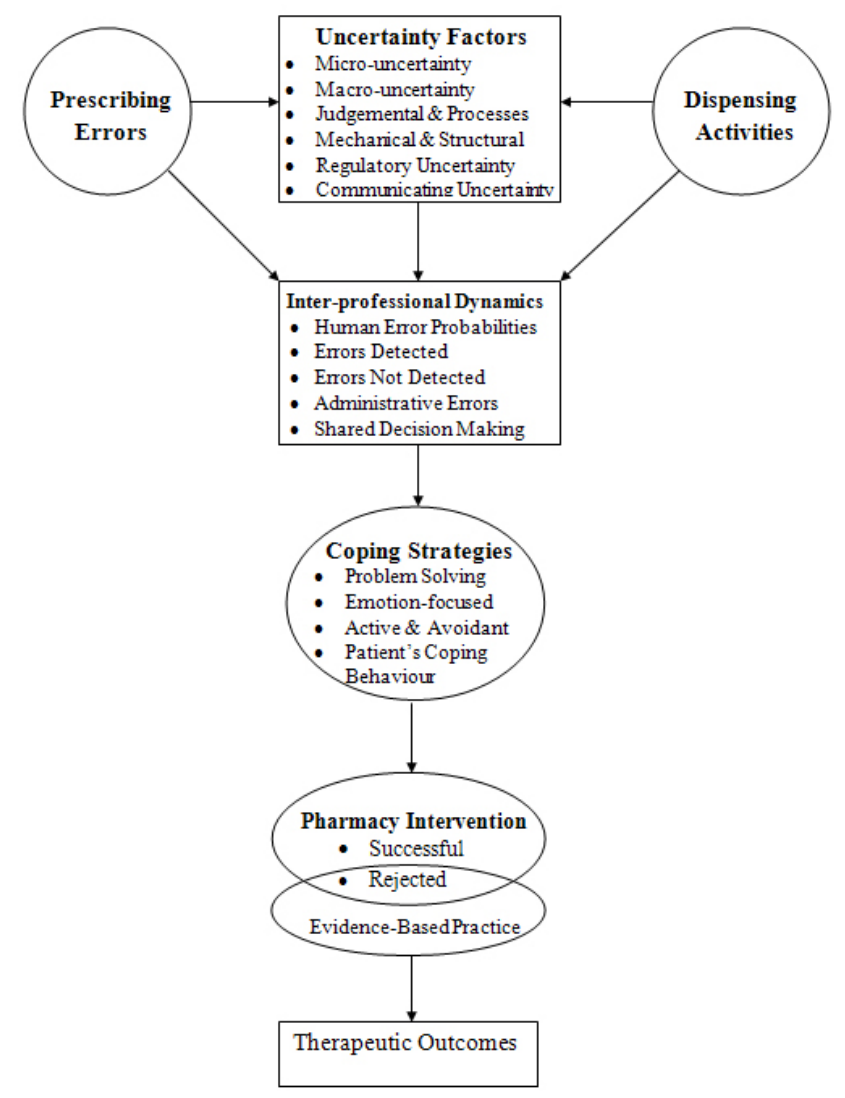

Figure 1. Prescribing errors and uncertainty: coping strategies of physicians \& pharmacists

The ability to disclose error is highly dependent on the maturity of the health professional (physician), ${ }^{[37]}$ but there seems to be unwillingness to discuss prescription errors with colleagues and patients, across the age strata and professional groups in our setting. Doctors and pharmacists also use other 
different coping strategies to deal with prescribing errors and uncertainty. Apart from health professionals (> 60\% each) using official reference books for error minimization, other coping methods represent very low percentages, with some having zero response to the respective stimuli. The medium and mode of communication between the two professional groups are unimpressive. Better coping strategies should be adopted ${ }^{[24]}$ by doctors and pharmacists in our setting, aimed at proactive, continuous, and meticulous monitoring and sensitization, ${ }^{[43-45]}$ to mitigate prescription errors and potential litigations. Where possible, they should cope with (new) uncertainties through a bounded rationality approach that aims for a reflective equilibrium incorporating internalistprescriptive and externalist-descriptive aspects, to turn good into better practice. ${ }^{[46]}$

Workshops and seminars on standard prescribing practice, including the development of prescription guidelines should be organized to educate junior doctors and young pharmacists on medication errors. Senior health professionals will also benefit from such training because of the increasing numbers of look-alike and sound-alike drugs, the uncertainty in generic drug quality, and robustness of some prescription products.

Figure 1 represents the relationship between prescribing errors, uncertainty, dispensing activities and the coping strategies of physicians and pharmacists towards patient wellness.

\section{Limitations and strengths of the study}

Limitations: Only doctors and pharmacists in one tertiary hospital were used for the study. Extending the study to other university hospitals in Nigeria would present more generalized results. Individual perceptions of prescription errors by the professional groups and reliance on memory in reporting the prevalence of errors may introduce bias to the assessment of the parameters. The variations in the years of experience in the two professional groups could affect respondents' perceptions and knowledge of prescribing errors. Health professionals' willingness to report prescription errors varies from country to country. Reluctance to disclose prescription errors and uncertainty could underestimate their prevalence and reported coping behaviours. The peculiarities of the geographical area where the research was carried out in terms of liability climate, variations in the complexities of documentation, reporting, and varied use of technology in the practice environment would limit the generalization of the results.

Strengths: The study compares coping strategies of two counterpart health care professionals using similar dimensions of medication errors and uncertainty. The study also shows the possibility of solving medication related problems from a two-pronged approach of care professionals. Convenience samples within a health care institution were used to reduce the time-line and cost of the research.

Implications: Physicians, pharmacists, nurses, and patients would benefit from any organized training programme, aimed at reducing medication errors and uncertainty to the barest minimum, and improving inter-professional collaboration. However the integration of training programmes that involve all stakeholders in the care-process and their effectiveness requires constant evaluation, for optimum result.

\section{Conclusions}

Doctors and pharmacists commit medication errors and tend to worry less about their consequences. They also tend to prescribe or dispense more when decision uncertainty is lowest. The low records of professional group encounters and communication towards resolving prescription errors and uncertainty are indicative of poor coping mechanisms to the stimuli. These could be due to lack of mutual trust on the core competencies of doctors as trained prescribers; and pharmacists as experts in drug-related problems, as well as poor patient relationships. The lapses in professional practices, compromised professional standards, slack in professional commitment and sub-optimal work environment could have generated a working culture that is far from ideal. There is need for more research into the root causes and extent of this divide, aimed at using available resources in a resource-limited environment, to foster a care-process that is team-oriented and less prone to prescription errors.

\section{ACKNOWLEDgements}

The doctors and pharmacists who filled the research instrument used for the study in the hospital are hereby acknowledged. The research was funded by the authors.

\section{CONFLicts OF INTEREST Disclosure}

The authors declare that they have no competing interests.

\section{REFERENCES}

[1] Aronson JK. Medication errors: definitions and classification. $\mathrm{Br}$ J Clin Pharmacol. 2009; 67(6): 599-604. PMid: 19594526. http: //dx.doi.org/10.1111/j.1365-2125.2009.03415.x [13 January 2016 , date last accessed]

[2] Aronson JK. Medication errors: what they are, how they happen, and 
how to avoid them. QJM: An International Journal of Medicine. 2009; 102(8): 513-521. Available from: www.qjmed.oxfordjournals . o rg/content/102/8/513 [14 January 2016, date last accessed]

[3] National Coordinating Council for Medication Error Reporting and Prevention. 2016. Available from: www.nccmerp.org/about-med ication-errors [13 January 2016, date last accessed]

[4] Lum E, Mitchell C, Coombes I. The competent prescriber: 12 core competencies for safe prescribing. Australian Prescriber. An Independent Review. 2013; 36(1): 13-16. Available from: www . austra lianprescriber . com/magazine/36/1/13/6 [15 January 2016, date last accessed]

[5] Velo GP, Minuz P. Medication errors: prescribing faults and prescription errors. Br J Clin. Pharmacol. 2009; 67(6): 624-628. PMid: 19594530. http://dx.doi.org/10.1111/j.1365-2125.2009 .03425.x [13 January 2016, date last accessed]

[6] Dobrzanski S, Hammond I, Khan G, et al. The nature of hospital prescribing errors. British Journal of Clinical Governance. 2002; 7 (3): 187-193. http://dx.doi.org/10.1108/1466410021043 8271 [15 February 2015, date last accessed]

[7] Sewal RK, Singh PK, Pratash A, et al. A prospective study to evaluate awareness about medication errors among health-care personnel representing North, East, West Regions of India. International Journal of Applied and Basic Medical Research 2014; 4(1): 42-46. Available from: https://www.researchgate.net/publication/26056 0404 [13 Jan 2016, date last accessed]

[8] Ross S, Ryan C, Duncan BM, et al. Perceived causes of prescribing errors by junior doctors in the hospital in-patients: a study from the PROJECT programme. BMJ Quality and Safety. 2013; 22(2): 97-102. PMid: 23112288. http://dx.doi.org/10.1136/bmjqs $-2012-001175$

[9] Alvesson HM, Lindelow M, Khanthaphat B, et al. Coping with uncertainty during health-care-seeking in Lao PDR. BMC International Health and Human Rights. 2013; 13: 28. PMid: 23777408. http://dx.doi.org/10.1186/1472-698X-13-28 [29 August 2014, date last accessed]

[10] Thompson C, Dowding D. Responding to uncertainty in nursing practice. International Journal of Nursing Studies. 2001; 38: 609615. http://dx.doi .org/10.1016/S0020-7489(00)00103-6 [27 November 2014, date last accessed]

[11] Oishi A, Murtagh FE. The challenges of uncertainty and interprofessional collaboration in palliative care for non- cancer patients in the community: a systematic review of views from patients, carers and health-care professionals. Palliative Medicine. 2014; 28(9): 10811098. PMid: 24821710. http://dx.doi.org/10.1177/0269216 314531999 [15 October 2014, date last accessed]

[12] Baumann AO, Deber RB, Thompson II. Overconfidence among physicians and nurses: the micro-uncertainty phenomena. Social Science and Medicine. 1991; 32(2): 167-174. http://dx.doi .org/10.10 16/0277-9536(91)90057-J

[13] Schwartz LM, Woloshin S. Characterizing and communicating uncertainty in the assessment of benefits and risks of pharmaceutical products: workshop summary. Forum on Drug Discovery, Development, and Translation; Board of Health Sciences Policy; Institute of Medicine. Washington (DC): National Academies Press (US); 2014 Available from: www.ncbi.nlm.nih.gov/books/NBK264317/

[14] Kramer DA. An uncertain prescription-medical malpractice actions in Louisiana. Louisiana Law Review. 2012; 72(2). Available from: digitalcommons. law. Isu.edu/cgi/viewcontent.cgi ?article=3061\&context=lalrev [18 May 2015, date last accessed]

[15] Schneider A, Wübken M, Linde K, et al. Communicating and dealing with uncertainty in general practice: The association with neuroticism.
PLOS ONE. 2014; 9(7): e102780. http://dx.doi.org/10.1371 /journal.pone.0102780 [20 August 2015, date last accessed]

[16] O'Riordan M, Dahinden A, Aktürk Z, et al. Dealing with uncertainty in general practice: an essential skill for the general practitioner. Quality in Primary Care. 2011; 19: 175-181.

[17] Hellström J, Rudholm N. Uncertainty in the generic versus brand name prescription decision. Empir Econ. 2010; 38(3): 503-521. ht tp://dx.doi.org/10.1007/s00181-009-0277-7 [20 August 2015, date last accessed]

[18] Nevalainen M, Kuikka L, Pitkälä K. Medical errors and uncertainty in the primary healthcare: a comparative study of coping strategies among young and experienced GPs. Scand J Prim Health Care [Internet]. 2014; 32(2): 84-89. PMid: 24914458. http://dx.doi.org /10.3109/02813432.2014.929820

[19] Grabber M, Berner EE. Diagnostic error: is overconfidence the problem? American Journal of Medicine. 2008; Suppl 5.

[20] Ryan C, Ross S, Davey P, et al. Prevalence and causes of prescribing errors: the prescribing outcomes for trainee doctors engaged in clinical training (PROJECT) study. PLoSONE. 2014; 9(1). http://dx.d oi .org/10.1371/journal .pone.0079802 [15 March 2015, date last accessed]

[21] Gallagher TH, Waterman AD, Ebers AG, et al. Patients' and physicians' attitudes regarding the disclosure of medical errors. Journal America Medical Association. 2003; 289: 1001-1007. PMid: 12597752. http://dx.doi.org/10.1001/jama.289.8.1001

[22] Engel KG, Rosenthal M, Sutclifffe M. Residents' responses to medical error: coping, learning, and change. Academic Medicine. 2006; 81: 86-93. PMid: 16377827. http://dx.doi.org/10.1097/000 01888-200601000-00021

[23] Prosser H, Almond S, Walley T. Influences on GPs' decisions to prescribe new drugs- the importance of who says what. Family Practice. 2003: 20(1): 61-68. PMid: 12509373. http://dx.doi.org/10. 1093/fampra/20.1.61 [20 August, 2015, date last accessed]

[24] Folksman S, Lazarus RS, Dunkel-Schetter C, et al. Dynamics of a stressful encounter: cognitive appraisal, coping and encounter outcomes. Journal of Personality and Social Psychology. 1986; 50: $992-$ 1003. http://dx.doi.org/10.1037/0022-3514.50.5.992

[25] American Society of Hospital Pharmacists (ASHP) Guidelines for preventing medication errors in hospitals. 1993; 217-219. Available from: https://www .ashp.org/DocLibrary/BestPractices/ MedMisGdlHosp.aspx [20 August 2015, date last accessed]

[26] Barber N, Rawlins M, Dean FB. Reducing prescribing error: Competence, control, and culture. Quality \& Safety in Health Care. 2003; 12(1): suppl i29-i32.

[27] Gleason KM, McDaniel MR, Feinglass J. Results of the medications at transitions and clinical handoffs (MATCH) study: an analysis of medication reconciliation errors and risk factors at hospital admission. Journal of General Internal Medicine. 2010; 25: 441-447. PMid: 20180158. http://dx.doi.org/10.1007/s11606-010 $-1256-6$

[28] Keers RN, Williams SD, Vattakatuchery JJ, et al. Prevalence, nature and predictors of prescribing errors in mental health hospitals: a prospective multicentre study. BMJ Open. 2014; 4: e006084 . http: //dx.doi.org/10.1136/bmjopen-2014-006084 [25 May 2015, date last accessed]

[29] Murtala Akanbi Y, Babangida L, Usman Abba I, et al. Comparative study of the state of literacy in Nigeria and Cuba. European Scientific Journal. 2013; 9(19): 1857-7431. Available from: eurojour nal.org/index.php/esj/article/download/1541/1548 [30 September 2015, date last accessed]

[30] Portefield A, Engelbert K, Coustasse A. Electronic prescribing: improving the efficiency and accuracy of prescribing in the ambulatory 
care setting. Perspectives in Health Information Management. 2014: 1-13. Available from: http://www.perspectives.ahima.org /electronic-prescribing-improving... [15 January 2016, date last accessed]

[31] Elsaid KA, Garguilo S, Collins CM. Chemotherapy e-prescribing: opportunities and challenges. Dovepress. 2015. Available from: https: //www. dovepress . com/chemotherapy-eprescribing . . . [15 January 2016, date last accessed]

[32] Thomas CP, Kim M, McDonald A, et al. Prescribers' expectations and barriers to electronic prescribing of controlled substances. Journal of American Medical Informatics Association. 2012; 19(3): 375-381. PMid: 21946239. http://dx.doi.org/10.1136/amiajnl-201 1-000209

[33] Omotosho A, Omotanwa A, Olaniyi OM, et al. A secure electronic prescription system using steganography with encryption key implementation. International Journal of Computer and Information Technology. 2014; 3(5): 980-986.

[34] Ajemigbitse AA, Omole MK, Osi-Ogbu OF, et al. A qualitative study of causes of prescribing errors among junior medical doctors in a Nigeria in- patient setting. Annals of African Medicine. 2013; 12(4): 223-231. PMid: 24309411. http://dx.doi.org/10.4103/159 6-3519. 122691

[35] Starmer AJ, Spector ND, Srivastava R, et al. Changes in medical errors after implementation of a handoff program. New Engl J. Med. 2014; 371(19): 1803-1812. PMid: 25372088. http://dx.doi.org /10.1056/NEJMsa1405556

[36] Kühn GJ. Diagnostic errors. Academic Emergency Medicine. 2002; 9: 740-750. PMid: 12093717. http://dx.doi.org/10.1111/j .1553-2712.2002.tb02155.x

[37] Crook ED, Stellini M, Levine D, et al. Case studies in ethics from the G.V. "Sonny" Montgomery VA Medical Centre and the University of Mississippi Medical Center. Am J Med Sci. 2004; 327: 33-37. PMid: 14722394.

[38] Lewis PJ, Tully MP. Uncomfortable prescribing decisions in hospitals: the impact of teamwork. Journal of Royal Society of Medicine.
2009; 102(11): 481-488. PMid: 19875537. http://dx.doi.org /10.1258/jrsm.2009.090150 [12 June 2015, date last accessed]

[39] Henry MS. Uncertainty, responsibility, and the evolution of the physician/ patient relationship. Journal of Medical Ethics. 2006; 32: 321323. PMid: 16731728. http://dx.doi.org/10.1136/jme. 200 5.013987 [14 May 2015, date last accessed]

[40] Steinberg EP, Luce BR. Evidence based? Caveat emptor! Health Affairs. 2005; 24: 80-92. PMid: 15647218. http://dx.doi.org /10.1377/hlthaff .24.1.80 [17 May 2015, date last accessed]

[41] Sedgwick P. Understanding P values. BMJ. 2014; 3349: g4550. PMid: 25015369. http://dx.doi.org/10.1136/bmj.g4550

[42] Shanafelt TD, Balch CM, Bechamps G, et al. Burnout and medical errors among American surgeons. Ann Surg. 2010; 25(6): 995-1000. PMid: 19934755. http://dx.doi.org/10.1097/SLA.0b013e3 181 bfdab3 [16 January 2016, date last accessed]

[43] Mohan P, Sharma AK, Panwar SS. Identification and quantification of prescription errors. Medical Journal Armed Forces India. 2014; 70: 149-153. PMid: 24843204. http://dx.doi.org/10.1016/j .mjafi.2014.01.002 [16 January 2016, date last accessed]

[44] Patanwala AE, Hays DP, Sanders AB, et al. Severity and probability of harm of medication errors intercepted by an emergency department pharmacist. Int J Pharm Pract. 2011; 19(5): 358-362. PMid: 21899616. http://dx.doi.org/10.1111/j.2042-7174. 2011.00122. $\mathrm{x}$

[45] Segal JB, Arevalo JB, Franke MF, et al. Reducing dosing errors and increasing clinical efficiency in Guatemala: first report of a novel mHealth medication dozing app in a developing country. BMJ Innovations. 2015; 1(3). [30 August 2015, date last accessed]

[46] Güth W, Kliemt H. How to cope with (new) uncertainties: a bounded rationality approach. Economics Discussion Papers. 2015; 46. Available from: http://www.economics-ejournal.org/economic s/discussionpapers/2015-46 [15 August 2015, date last accessed] 